Original Research

\title{
Chemical Composition and in vitro Evaluation of Cytotoxicity, Antioxidant and Antimicrobial Activities of Essential Oil Extracted from Myristica Fragrans Houtt
}

\author{
Moin ud Din ${ }^{1}$, Abid Ali², Muhammad Yasir ${ }^{3}$, Muhammad Idrees Jilani ${ }^{4}$, \\ Sanila Shoaib ${ }^{5}$, Muhammad Latif ${ }^{6}$, Aftab Ahmad ${ }^{7 *}$, Saima Naz ${ }^{8}$, Farheen Aslam?, \\ Munawar Iqbal ${ }^{3}$, Arif Nazir ${ }^{3 * *}$ \\ ${ }^{1}$ Department of Chemistry, Govt. Postgraduate College of Science, Faisalabad, Pakistan \\ ${ }^{2}$ Department of Allied Health Sciences, The University of Lahore, Gujrat Campus, Pakistan \\ ${ }^{3}$ Department of Chemistry, The University of Lahore, Lahore, Pakistan \\ ${ }^{4}$ Department of Chemistry, University of Sahiwal, Sahiwal, Pakistan \\ ${ }^{5}$ Institute of Microbiology, University of Agriculture, Faisalabad, Pakistan \\ ${ }^{6}$ Division of Science and Technology, Department of Zoology, University of Education Lahore, \\ Multan Campus, Pakistan \\ ${ }^{7}$ Department of Biochemistry/Centre for Advanced Studies in Agriculture and Food Security (USPCASAFS), \\ University of Agriculture, Faisalabad, Pakistan \\ ${ }^{8}$ Division of Science and Technology, Department of Chemistry, University of Education Lahore, \\ Multan Campus, Pakistan \\ ${ }^{9}$ Department of Biotechnology, Lahore College for Women University, Lahore, Pakistan
}

Received: 7 February 2020

Accepted: 27 June 2020

\begin{abstract}
This paper focuses on the chemical composition, antioxidant, cytotoxicity (brine shrimp lethality and hemolytic assay) and antimicrobial activities of essential oil of mace (Myristica fragrans) oil. We have found 33 compounds as evidenced by GC-MS analysis. The most prominent of these compounds are safrole, $\beta$-phellandrene, 3-p-menthene and L-terpinen-4-ol. Antioxidant activity of the mace essential oil was examined using the free radical scavenging assay $(21.95 \mu \mathrm{g} / \mathrm{mL}), \beta$-carotene in linoleic acid and percent inhibition in linoleic acid (67.9 \%) system. Four pathogenic fungi, 4 gram positive and 2 gram negative bacteria were used for antimicrobial activity of oil. Aspergillus niger and Streptococcus mutans proved to be most sensitive with MIC values i.e. 1.01 and $1.72 \mathrm{mg} / \mathrm{mL}$, respectively. The mace
\end{abstract}

*e-mail: aftab.ahmad@uaf.edu.pk

**e-mail: malikanphd2013@yahoo.com 
essential oil exhibited toxicity with $\mathrm{LC}_{50}$ value $31.05 \mu \mathrm{g} / \mathrm{mL}$ cytotoxicity against nauplii of Artemia salina and minimum hemolytic activity was recorded as $5.21 \%$ at $0.5 \mathrm{mg} / \mathrm{mL}$ concentration.

Keywords: mace, essential oil, Artemia salina, hemolytic assay, probit analysis

\section{Introduction}

Free radicals are responsible for the reactions occurring in food systems. Normally the free radicals are integral part of physiology and are present either in the form of reactive, short lived oxygen and nitrogen species [1-3]. Overproduction of these reactive species occurs due to oxidative stress caused by imbalance of antioxidant defence system in human beings [46]. In spite of having a variety of methods for food presservation, the deterioration of food and other eatables is still a big issue for industrialists and consumers. Despite of these preservation methods, microbial contamination and peroxidation of lipids in food items results in poisoning of food and reduction in shelf life. It also leads to different food borne diseases and economic losses [7]. That is why people are in search of substances of natural origin like extracts and essential oils which could be used as food preservatives [8].

To prolong the shelf life of the foods with polyunsaturated moities, the antioxidants has been used excessively in food industry. Antioxidants can be very effective alternate for food storage and slowing down its oxidation process [9]. The frequent use of synthetic antioxidants has now been restricted due to their carcinogenic effect towards health. Therefore finding non-carcinogenic antioxidants has been a matter of great interest for scientists which could be effective and have the ability to protect human body against free radicals and their lethal effects by which they become responsible for chronic diseases [10]. A large number of studies have been carried out so far in which a variety of plant based antioxidant sources have been explored [11]. In addition, oxidative damage in our body can be prevented by formulated these natural antioxidants as functional foods and nutraceuticals.

Essential oils have got the attention of scientists as they have proved to be a potential source of preservation of food, pharmaceuticals, alternative medicines and natural therapies. Besides these, they have shown several pharmacological effects, like hepatoprotective, carminative, spasmolytic, anti-carcinogenic and antiviral effects. The attention towards these is also due to their behaviour against microbes and oxidants which proved their action for food security.

The mace tree is a large, leafy evergreen plant, cultivated in tropical regions and native to Indonesia and West Indies. There are multiple applications of mace oils e.g. flavouring of meat products, liquors and perfumery products. A lot of work has been done on biological activities of nutmeg essential oil but as for as mace is concerned, only extracts have been evaluated [12].
The goal of the current research was to find out the composition, various other properties including antioxidant, cytotoxic and antimicrobial properties of essential oil of mace extracted by hydro distillation.

\section{Materials and Methods}

The sample of seeds of Myristica fragrans was collected from Pothohar region of Pakistan. Mace was fleshy red, net like skin over seeds, separated and dried. Hydrodistillation method has used for the extraction of essential oils by boiling the plant material in wáter [13]. For this purpose $200 \mathrm{~g}$ of dried mace was dipped into wáter in and boiled for $3 \mathrm{~h} 10 \mathrm{~min}$. The oil due to its hydrophobic nature made a separate layer and was separated using a separatory funnel. Furthermore, the wáter contents of oil was removed using anhydrous sodium sulphate, followed by filtration and then filtrate was stored in sealed glass bottle at $4{ }^{\circ} \mathrm{C}$. Different physical parameters like colour, refractive index, solubility and density of oil were determined using standard methods [14].

Essential oil sample was analyzed using HP 5890 GC equipped with MSD 5972 [15]. Antioxidant activity of the mace essential oil was determined with slight modifications [16]. The percent Inhibition was calculated.

$$
\% I=100 \times\left(\text { Ac } \times \frac{\mathrm{As}}{\mathrm{Ac}}\right)
$$

...where A stand for absorbance, while $\mathrm{c}$ and $\mathrm{s}$ in subscript indicate control and sample respectively. The antioxidant activity was denoted as $\mathrm{IC}_{50}(\mu \mathrm{g} /$ $\mathrm{ml}$ ); the lesser the $\mathrm{IC}_{50}$ value, the higher is antioxidant activity [17]. The thiocyanate method was used for measurement of oxidation [18]. Antioxidant activity was also assessed by bleaching $\beta$-carotene/linoleic acid emulsion system with slight modification [19]. The antimicrobial activity of sample was tested against 4 gram-positive bacteria: Bacillus subtilis, Lactobacillus rhamnosus, Staphylococcus aureus, Streptococcus mutans, 2 gram-negative bacteria: Escherichia coli and Pasteurella multocida and 4 pathogenic fungi: Alternaria alternata, Aspergillus flavus, Aspergillus niger and Ganoderma lucidum. Antimicrobial activities were determined following the methodology of National Committee for Clinical Laboratory Standards (NCCLS) [20]. The minimum inhibitory concentration (MIC) was determined using 96-well plates by following the methodology of NCCLS [21]. The brine shrimp lethality test was performed following procedure by McLaughlin 
[22]. The hemolytic activity was investigated using human and bovine erythrocytes using the method reported by Sharma and Sharma [23]. The haemolysis was calculated as follow:

$$
\% \text { Haemolysis }=\left(\frac{\mathrm{Hb}_{\mathrm{ABS}}}{\mathrm{Hb} 100 \% \mathrm{ABS}}\right) \times 100
$$

For statistical analysis, data obtained from brine shrimp lethality assay was organized by dose, the number of subjects, and the number of lethal events. Probit Analysis was performed using Proc Probit log10 (SAS/STAT 9.3_M1, SAS Institute, Inc. Cary, NC). Results for all statistically significant data also include 95\% fiducial limits.

\section{Results and Discussion}

The colour and yield of oil was pale brown and $1.75 \%$ respectively. Similarly, some other physical

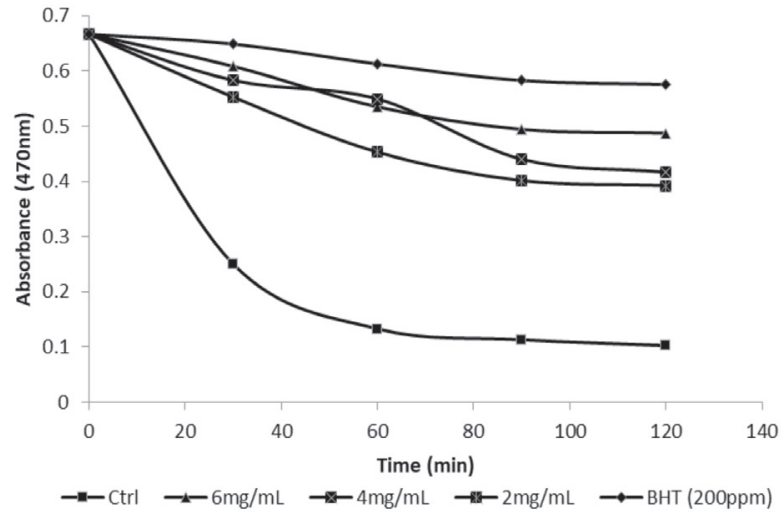

Fig. 1. $\beta$-Carotene bleaching inhibition activities of Mace essential oil and BHT.

parameters like refractive index $(1.364 \pm 0.004)$ and density $\left(0.95 \mathrm{~g} / \mathrm{cm}^{3}\right)$ were also calculated. 33 compounds were identified representing about $98 \%$ of total weight by GC-MS analysis of the mace essential oil. The major

Table 1. Antimicrobial activity of mace essential oil.

\begin{tabular}{|c|c|c|c|}
\hline Tested organisms & Mace essential oil & Rifampicin & Terbinafine \\
\hline \multicolumn{4}{|c|}{ Inhibition zone (mm) } \\
\hline B. subtilis & $6.7 \pm 1.5$ & $10.8 \pm 2.1$ & - \\
\hline L. rhamnosus & $8.0 \pm 1.0$ & $15.5 \pm 0.8$ & \\
\hline S. aureus & $10.7 \pm 1.5$ & $15.1 \pm 1.0$ & - \\
\hline S. mutans & $14.3 \pm 0.5$ & $13.4 \pm 0.7$ & \\
\hline E. coli & $10.3 \pm 1.1$ & $9.6 \pm 1.3$ & - \\
\hline P. multocida & $8.3 \pm 1.1$ & $11.6 \pm 1.5$ & - \\
\hline A. niger & $21.3 \pm 1.5$ & - & $21.7 \pm 1.2$ \\
\hline A. flavus & $6.3 \pm 0.5$ & - & $11.4 \pm 1.4$ \\
\hline A. alternata & $11.7 \pm 0.5$ & - & $14.2 \pm 0.8$ \\
\hline G. lucidum & $8.7 \pm 1.5$ & - & $9.1 \pm 0.4$ \\
\hline \multicolumn{4}{|c|}{ Mínimum inhibitory concentration (MIC) $\mathrm{mg} / \mathrm{mL}$} \\
\hline B. subtilis & $3.44 \pm 0.3$ & $1.72 \pm 0.2$ & - \\
\hline L. rhamnosus & $4.06 \pm 0.2$ & $2.81 \pm 0.3$ & - \\
\hline S. aureus & $2.81 \pm 0.1$ & $2.19 \pm 0.2$ & - \\
\hline S. mutans & $1.72 \pm 0.2$ & $2.03 \pm 0.1$ & - \\
\hline E. coli & $1.88 \pm 0.1$ & $2.34 \pm 0.2$ & - \\
\hline P. multocida & $2.5 \pm 0.1$ & $2.03 \pm 0.1$ & - \\
\hline A. niger & $1.01 \pm 0.2$ & - & $0.94 \pm 0.1$ \\
\hline A. flavus & $3.75 \pm 0.1$ & - & $2.81 \pm 0.2$ \\
\hline A. alternata & $2.81 \pm 0.2$ & - & $2.34 \pm 0.2$ \\
\hline G. lucidum & $2.03 \pm 0.2$ & - & $1.88 \pm 0.1$ \\
\hline
\end{tabular}

Valúes are means \pm standard deviation 
components were safrole $(49.09 \%), \quad \beta$-Phellandrene (18.27\%), 3-p-Menthene (10.76\%) and L-Terpinen-4-ol (3.35\%). Some other scientists have reported análysis of essential oil extracted from Myristica fragrans seed. They reported thirty-two compounds including sabinene (21.38\%), 4-terpineol (13.92\%), myristicin $(13.57 \%), \alpha$-pinene $(10.23 \%)$ and limonene $(5.57 \%)$ as main components [24].

The $\mathrm{DPPH} \cdot$ has been used as a useful tool for the evaluation of antioxidant capacity of different materials as it is a stable free radical. The underlying mechanism is either the hydrogen atom transfer or electron to DPPH $\bullet$ making it neutralized in an antioxidant and DPPH• interaction [25]. The decrease in $\mathrm{DPPH} \bullet$ concentration was noticeable due to change of its colour from purple to yellow which was measured in term of absorption taken by spectrophotometer at $515 \mathrm{~nm}$. The examined essential oil of mace reduced the stable, purple-coloured radical DPPH into its reduced form which was yellow coloured. Samples with lower $\mathrm{IC}_{50}$ values have strong antioxidant potential. In the present study, mace sample has shown good antioxidant property with $\mathrm{IC}_{50}=21.95 \mu \mathrm{g} / \mathrm{mL}$ compared to BHT with $\mathrm{IC}_{50}=3.46 \mu \mathrm{g} / \mathrm{mL}$. Chatterjee et al. [26] reported the extract from the mace essential oil has higher antioxidant activity. It was attributed to the presence of lycopane that boost the activity of whole extrat.

Kapoor et al. [18] also tested antioxidant potential of Myristica fragrans using DPPH and linoleic acid Inhibition assays. Inhibition by linoleic acid oxidation system through the thiocynate method was used to investigate the antioxidant activity of the samples from mace essential oil. Linoleic acid is an unsaturated fatty acid, when it undergoes oxidations, it oxidizes ferrous and ferric ions by different peroxides and resultantly forms complex with thiocyanate ions coming from ammonium thiocyanate. The concentration of the complex formed was determined by measuring the absorbance at $500 \mathrm{~nm}$ spectrophotometrically. Larger absorbance values exhibit more peroxides formation during the process and hence lower the antioxidant activity of that oil. All concentrations of essential oil showed appreciable inhibition, ranging from $19 \%$ to $68 \%$ and were compared with BHT whose inhibition was $81 \%$. It is clear that sample with concentration $50 \mu \mathrm{L} / \mathrm{mL}$ has maximum inhibition $68 \%$ while with $10 \mu \mathrm{L} / \mathrm{mL}$ the inhibition was $19 \%$. Mathew and Abraham also obtained similar findings using different concentrations of cinnamon extracts and percent inhibition increased from $81.8 \%$ to $93.3 \%$ with varying concentrations from $25-200 \mu \mathrm{g} / \mathrm{mL}$ [27].

Fig. 1 shows the bleaching of $\beta$-carotene by mace essential oil as antioxidant in linoleic acid system. The absence of antioxidants results in rapid discoloration of $\beta$-carotene and the antioxidant neutralizes linoleate or any other free radical and thus inhibits destruction of $\beta$-carotene present in the system [28]. The decrease in absorbance of $\beta$-carotene is inversly proportional to antioxidant activity and directly related to rate of linoleic acid oxidation. The control showed maximum colour depletion due to absence of sample.

Ten pathogenic microorganisms were used for antimicrobial activity of the mace essential oil and Table 1 shows the results of MIC measured using disc diffusion method. The results have shown that there is a remarkable activity in the case of some pathogens as compared to antibiotic. Among bacteria S. mutans and E. coli were most sensitive microorganisms showing largest inhibition zones $(14.3 \mathrm{~mm} \& 10.3 \mathrm{~mm})$ with lowest MIC values $(1.72 \mathrm{mg} / \mathrm{mL} \& 1.88 \mathrm{mg} / \mathrm{mL})$. The most dynamic and sensitive result has been revealed by $A$. niger with the lowest MIC value $(1.01 \mathrm{mg} / \mathrm{mL})$ and highest inhibition zone $(21.3 \mathrm{~mm})$.

Similar results have been reported by Shafiei et al. [29]. They reported the evaluation of mace, flesh extracts and seed of Myristica fragrans against strains of various pathogens. The extract of flesh was better tan seed and mace with reference to activity against the pathogens.

Mace essential oil has proven to be better candidate in regard to the brine shrimp lethality test with $\mathrm{LC}_{50}$ values of $31.05 \mu \mathrm{g} / \mathrm{mL}$ and showed the moderate activity in comparison with other essential oils. This different behaviour could be associated to the presence of safrole in higher concentrations. The results were found to be significant. Another study was reported for A. subulatum seed and rind oils. The test for cytotoxic behaviour was performed and both have shown moderate activity with the $\mathrm{LC}_{50}$ values of 28.1 and $15.0 \mu \mathrm{g} / \mathrm{mL}$, respectively [30].

Results of hemolytic activity have shown that essential oil of mace revealed taht the maximum hemolytic activity was found at $10 \mathrm{mg} / \mathrm{mL}$ while minimum was observed at $0.5 \mathrm{mg} / \mathrm{mL}$. The maximum values were $7.24 \%$ and $9.93 \%$ for bovine and human erythrocytes respectively while minimum values were recorded as $0.31 \%$ and $0.52 \%$ for bovine and human erythrocytes respectively. It is important to analyze the hemolytic activity of drugs. This could be useful indicator for cytotoxicity which determine whether pharmacological applications are viable [31, 32]. The mace essential oil showed less cytotoxicity compared to other plant oils and extracts. This peculiar feature recommend its suitability for pharmacological purpose especially at lower concentrations.

\section{Conclusions}

Mace from Pothohar region (Pakistan) was subjected to essential oil extraction (1.75 g/100 g). GC-MS analysis revealed that it was enriched with safrole (49.09 \%). Antioxidant and antimicrobial activities of mace oil was evaluated using various assays. The results have revealed its good potential as an antioxidant and antimicrobial agent in comparison with that of control. Cytotoxicity studies indicated that 
it showed little cytotoxic effect at lower doses which makes it suitable for its use as medicinal purposes.

\section{Conflict of Interest}

The authors declare no conflict of interest.

\section{References}

1. RASTKARI N., ESLAMI A., NASSERI S., PIROTI E., ASADI A. Optimizing Parameters on Nanophotocatalytic Degradation of Ibuprofen Using UVC/ZnO Processes by Response Surface Methodology. Pol. J. Environ. Stud. 26 (2), 785, 2017.

2. HAILU Y.M., ATLABACHEW M., CHANDRAVANSHI B.S., REDI-ABSHIRO M. Composition of essential oil and antioxidant activity of Khat (Catha edulis Forsk), Ethiopia. Chem. Int. 3 (1), 25, 2017.

3. HASSEN E.B., ASMARE A.M. Predictive performance modeling of Habesha brewery wastewater treatment plant using artificial neural networks. Chem. Int. 5 (1), 87, 2019.

4. MUNIR A., SULTANA B., BASHIR A., GHAFFAR A., MUNIR B., SHAR G.A., NAZIR A., IQBAL M. Evaluation of Antioxidant Potential of Vegetables Waste. Pol. J. Environ. Stud. 27 (2), 947, 2018.

5. QAMAR A., ASI R., IQBAL M., NAZIR A., ARIF K. Survey of Residual Pesticides in Various Fresh Fruit Crops: A Case Study. Pol. J. Environ. Stud. 26 (6), 2703, 2017.

6. SULEMAN M., NOUREN S., HASSAN S.M., FAIZ A.H., SAHR G.A., SOOMRO G.A., TAHIR M.A., IQBAL M., NAZIR A. Vitality and Implication of Natural Products from Viburnum Grandiflorum: an Eco-Friendly Approach. Pol. J. Environ. Stud. 27 (3), 1407, 2018.

7. ARSHAD M., QAYYUM A., SHAR G.A., SOOMRO G.A., NAZIR A., MUNIR B., IQBAL M. Zn-doped $\mathrm{SiO}_{2}$ nanoparticles preparation and characterization under the effect of various solvents: Antibacterial, antifungal and photocatlytic performance evaluation. J. Photochem. Photobiol. B: Biol. 185, 176, 2018.

8. LOIZZO M., TUNDIS R., CHANDRIKA U., ABEYSEKERA A., MENICHINI F., FREGA N. Antioxidant and antibacterial activities on foodborne pathogens of Artocarpus heterophyllus Lam. (Moraceae) leaves extracts. J. Food Sci. 75 (5), M291, 2010.

9. ROBY M.H.H., SARHAN M.A., SELIM K.A.-H., KHALEL K.I. Antioxidant and antimicrobial activities of essential oil and extracts of fennel (Foeniculum vulgare L.) and chamomile (Matricaria chamomilla L.). Ind. Crop. Prod. 44, 437, 2013.

10. IGWE O., NWAMEZIE F. Green synthesis of iron nanoparticles using flower extract of Piliostigma thonningii and antibacterial activity evaluation. Chem. Int. 4, 60, 2018.

11. CASTILHO P.C., SAVLUCHINSKE-FEIO S., WEINHOLD T.S., GOUVEIA S.C. Evaluation of the antimicrobial and antioxidant activities of essential oils, extracts and their main components from oregano from Madeira Island, Portugal. Food Cont. 23 (2), 552, 2012.

12. CHOO L.C., WONG S.M., LIEW K.Y. Essential oil of nutmeg pericarp. J. Sci. Food Agric. 79 (13), 1954, 1999.
13. DIN M.U., SARFRAZ R.A., SHAHID T. Biological activity-based assessment of essential oil emulsions. J. Food Proc. Preservat. 39 (6), 1452, 2015.

14. GUENTHER E. Determination of physical and chemical properties. The essential oils (Vol III). Toronto, New York and London. In.: D. Van Nostrand Comp., INC; 1960.

15. ADAMS R.P. Identification of essential oil components by gas chromatography/mass spectrometry, vol. 456: Allured publishing corporation Carol Stream, IL; 2007.

16. HUSSAIN A.I., ANWAR F., SHERAZI S.T.H., PRZYBYLSKI R. Chemical composition, antioxidant and antimicrobial activities of basil (Ocimum basilicum) essential oils depends on seasonal variations. Food Chem. 108 (3), 986, 2008.

17. HAJLAOUI H., MIGHRI H., NOUMI E., SNOUSSI M., TRABELSI N., KSOURI R., BAKHROUF A. Chemical composition and biological activities of Tunisian Cuminum cyminum L. essential oil: A high effectiveness against Vibrio spp. strains. Food Chem. Toxicol. 48 (8-9), 2186, 2010.

18. KAPOOR I., SINGH B., SINGH G., DE HELUANI C.S., DE LAMPASONA M., CATALAN C.A. Chemical composition and antioxidant activity of essential oil and oleoresins of nutmeg (Myristica fragrans Houtt.) fruits. Int. J. Food Prop. 16 (5), 1059, 2013.

19. CAO L., SI J.Y., LIU Y., SUN H., JIN W., LI Z., ZHAO X.H., LE PAN R. Essential oil composition, antimicrobial and antioxidant properties of Mosla chinensis Maxim. Food Chem. 115 (3), 801, 2009.

20. STANDARDS NNCFCL. Performance standards for antimicrobial susceptibility testing: eleventh informational supplement. In.: National Committee for Clinical Laboratory Standard Wayne, PA, USA; 2001.

21. FRITSCHE T.R., MCDERMOTT P.F., SHRYOCK T.R., WALKER R.D. Agar dilution and disk diffusion susceptibility testing of Campylobacter spp. J. Clin. Microbiol. 45 (8), 2758, 2007.

22. MCLAUGHLIN J.L. Bench-top bioassays for the discovery of bioactive compounds in higher plants. Brenesia (34), 1, 1990.

23. SHARMA P., SHARMA J.D. In vitro hemolysis of human erythrocytes - by plant extracts with antiplasmodial activity. J. Ethnopharmacol. 74 (3), 239, 2001.

24. SUBARNAS A., APRIYANTONO A., MUSTARICHIE R. Identification of compounds in the essential oil of nutmeg seeds (Myristica fragrans Houtt.) that inhibit locomotor activity in mice. Int. J. Mol. Sci. 11 (11), 4771, 2010.

25. AL-REZA S.M., RAHMAN A., SATTAR M., RAHMAN M.O., FIDA H.M. Essential oil composition and antioxidant activities of Curcuma aromatica Salisb. Food Chem. Toxicol. 48 (6), 1757, 2010.

26. CHATTERJEE S., NIAZ Z., GAUTAM S., ADHIKARI S., VARIYAR P.S., SHARMA A. Antioxidant activity of some phenolic constituents from green pepper (Piper nigrum L.) and fresh nutmeg mace (Myristica fragrans). Food Chem. 101 (2), 515, 2007.

27. MATHEW S., ABRAHAM T.E. Studies on the antioxidant activities of cinnamon (Cinnamomum verum) bark extracts, through various in vitro models. Food Chem. 94 (4), 520, 2006

28. KAMATH V., RAJINI P. The efficacy of cashew nut (Anacardium occidentale L.) skin extract as a free radical scavenger. Food Chem. 103 (2), 428, 2007. 
29. SHAFIEI Z., SHUHAIRI N.N., MD FAZLY SHAH YAP N., HARRY SIBUNGKIL C.-A., LATIP J. Antibacterial activity of Myristica fragrans against oral pathogens. Evid. Compl. Alternat. Med. 2012, 62, 2012

30. SATYAL P., DOSOKY N.S., KINCER B.L., SETZER W.N. Chemical Compositions and Biological Activities of Amomum subulatum Essential Oils from Nepal. Nat. Prod. Comm. 7 (9), 1233, 2012.
31. IWUOHA G.N., AKINSEYE A. Toxicological symptoms and leachates quality in Elelenwo, Rivers State, Nigeria. Chem. Int. 5 (3), 198, 2019.

32. ALASADI M., KHAILI F.I., AWWAD AM. Adsorption of $\mathrm{Cu}(\mathrm{II}), \mathrm{Ni}(\mathrm{II})$ and $\mathrm{Zn}(\mathrm{II})$ ions by nano kaolinite: Thermodynamics and kinetics studies. Chem. Int. 5 (4), $258,2019$. 